\title{
Influence of 1-butyl-3-methylimidazolium Chloride on the Ethanol Fermentation Process of Pichia pastoris GS115
}

\author{
Wenjing Huang, Yanjie Tong, Wangxiang Huang, Ke Wang, Qiming Chen, Yuanxin Wu and \\ Shengdong $\mathrm{Zhu}^{*}$
}

\begin{abstract}
Key Laboratory for Green Chemical Process of Ministry of Education, Hubei Key Laboratory of Novel Chemical Reactor and Green Chemical Technology, School of Chemical Engineering and Pharmacy, Wuhan Institute of Technology, Wuhan 430073, P.R. China
\end{abstract}

\begin{abstract}
To evaluate the influence of 1-butyl-3-methylimidazolium chloride $([\mathrm{Bmim}] \mathrm{Cl})$ on the ethanol fermentation process of Pichia pastoris GS115, this paper investigated the yeast growth, ethanol formation and the fermentable sugars consumption during the ethanol fermentation process of Pichia pastoris GS115 at different [Bmim]Cl concentrations in the medium. The results indicated that the $[\mathrm{Bmim}] \mathrm{Cl}$ had no influence on the ethanol fermentation process at its concentration less than 0.0001 g. $\mathrm{L}^{-1}$. The $[\mathrm{Bmim}] \mathrm{Cl}$ inhibited the yeast growth and had a negative effect on ethanol formation at its concentration higher than 0.0001 g. $\mathrm{L}^{-1}$. The final biomass and ethanol concentration, and the overall ethanol yield from the fermentable sugars all decreased with its concentration increasing. The yeast growth was very slow and nearly no ethanol formed when its concentration reached $5 \mathrm{~g} . \mathrm{L}^{-1}$. Compared to Saccharomyces cerevisiae, the growth of Pichia pastoris GS115 was more sensitive to the $[\mathrm{Bmim}] \mathrm{Cl}$, and its ethanol fermentation had lower final ethanol concentration and overall ethanol yield from fermentable sugars at the same $[\mathrm{Bmim}] \mathrm{Cl}$ concentration. This work provides useful information on selecting suitable strains for ethanol fermentation containing the $[\mathrm{Bmim}] \mathrm{Cl}$ in the medium.
\end{abstract}

Keywords: [Bmim]Cl, ethanol fermentation, ionic liquid, Pichia pastoris GS115.

\section{INTRODUCTION}

Lignocellulosic materials are the most economical and highly renewable natural resources in the world. Lignocellulosic ethanol production has drawn much attention in recent years [1]. Ethanol is not only used as a clean and renewable energy but also as a versatile chemical. Its consumption is to keep increasing steadily. It is now one of the most widely used transport bio-fuels. In general, production of lignocellulosic ethanol needs to firstly convert the carbohydrates in lignocellulosic materials to the fermentable sugars, and then ferment the obtained fermentable sugars to ethanol. Due to the complex structure of lignin and hemicellulose with cellulose in lignocellulosic materials, the conversion of carbohydrates in lignocellulosic materials to the fermentable sugars becomes the control procedure in the lignocellulosic ethanol production. Although lots of studies have been carried out, there are still facing great challenges in converting the carbohydrates in lignocellulosic materials to the fermentable sugars in an industrial scale based on economical and environmental consideration $[1,2]$. Use of ionic liquids has provided a new technical tool to convert the carbohydrates in lignocellulosic materials to the fermentable sugars for ethanol production [3]. Some studies have indicated that the

\footnotetext{
*Address correspondence to this author at the Key Laboratory for Green Chemical Process of Ministry of Education, Hubei Key Laboratory of Novel Chemical Reactor and Green Chemical Technology, School of Chemical Engineering and Pharmacy, Wuhan Institute of Technology, Wuhan 430073, P.R. China; Tel: +86-27-87195671; Fax: +86-27-87195671;

E-mail: zhusd2003@21cn.com
}

carbohydrates in lignocellulosic materials can be efficiently converted to the fermentable sugars using ionic liquid technology [4]. The conversion of carbohydrates in lignocellulosic materials to the fermentable sugars using ionic liquid technology has three technical routes: ionic liquid pretreatment of lignocellulosic materials [5], enzymatic hydrolysis of lignocellulosic materials in ionic liquid medium, and chemical hydrolysis of of lignocellulosic materials in ionic liquid medium [6-8]. Whatever technical route was employed, some ionic liquids remained in the obtained fermentable sugars were inevitable. Therefore, it is extremely important to know how the residual of ionic liquids in fermentable sugars will affect the subsequent ethanol fermentation process, because the 1- butyl-3-methylimidazolium chloride $([\mathrm{Bmim}] \mathrm{Cl})$ is one of the most widely-used and cheapest ionic liquid in conversion the carbohydrates in lignocellulosic materials to the fermentable sugars for ethanol production, it was often chosen as a model ionic liquid to study the influence of its residual in fermentable sugars on the subsequent ethanol fermentation process. Some studies have been carried out on the effects of $[\mathrm{Bmim}] \mathrm{Cl}$ on the growth and ethanol fermentation of Saccharomyces cerevisiae in our previous work [9, 10]. Apart from Saccharomyces cerevisiae, Pichia pastoris is also often used for ethanol fermentation $[11,12]$. In order to select the suitable strains for ethanol fermentation containing the $[\mathrm{Bmim}] \mathrm{Cl}$ in the medium, the influence of $[\mathrm{Bmim}] \mathrm{Cl}$ on the growth and ethanol fermentation of Pichia pastoris GS115 will be investigated in this work and compared with our previous studies. 


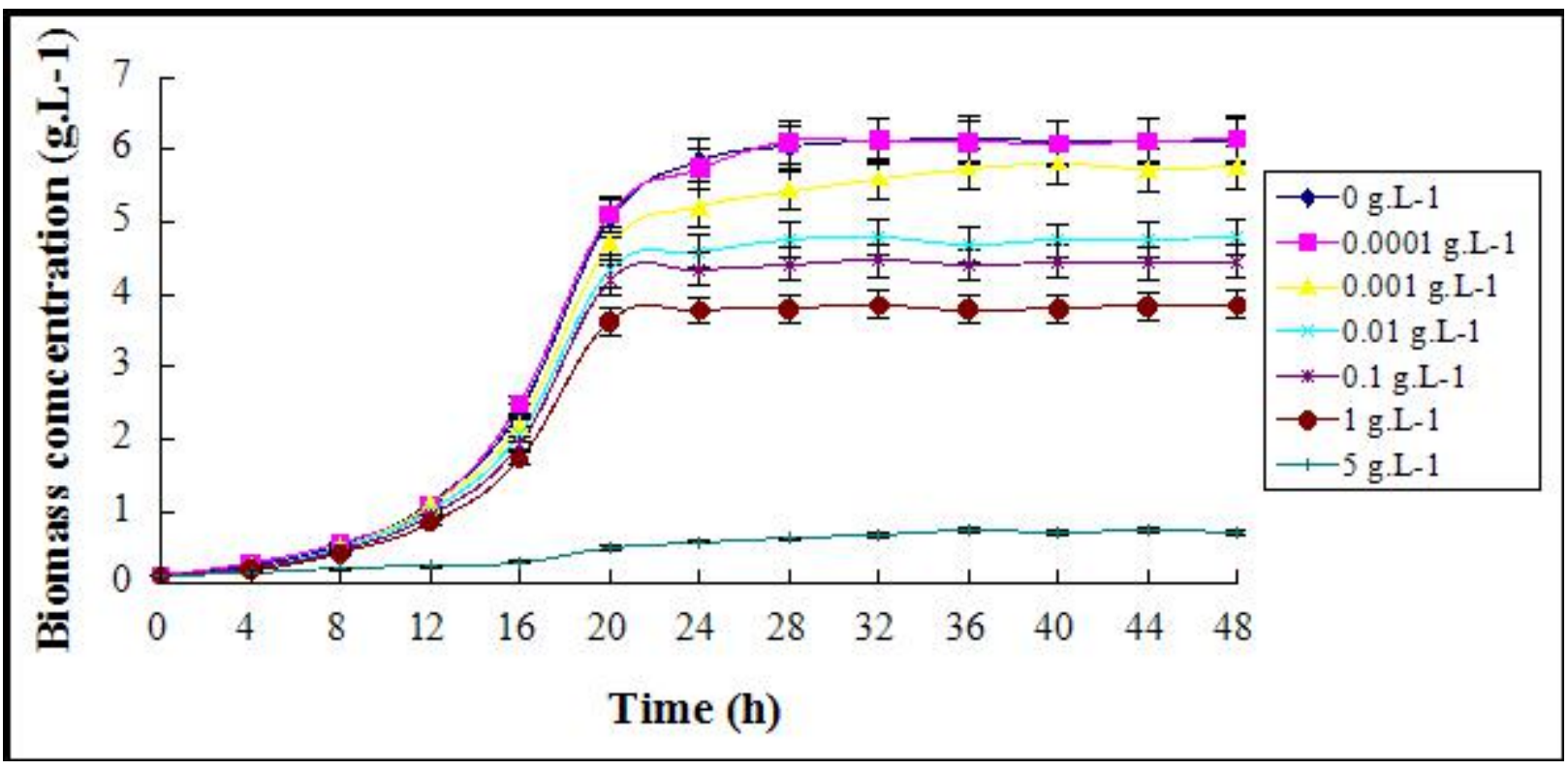

Fig. (1). Growth curves of Pichia pastoris GS115 for ethanol fermentation process under different [Bmim]Cl concentrations.

\section{MATERIALS AND METHODS}

All experiments were carried out three times, and the given numbers are the mean values, whose relative errors are within $\pm 5 \%$.

\subsection{Micro-Organism, Medium and Culture Conditions}

The Pichia pastoris GS115 was used throughout this study. The medium and culture conditions were the same as our previous work for ethanol fermentation of Saccharomyces cerevisiae [9, 10]. During the ethanol fermentation process of Pichia pastoris GS115, some samples were taken at regular intervals for later analysis.

\subsection{Analytical Methods}

The samples taken from the ethanol fermentation process of Pichia pastoris GS115 were used to determine the concentration of biomass, ethanol and the fermentable sugars. Biomass concentration was determined by the dry weight method [13]. Ethanol content was determined by gas chromatography [14] and the fermentable sugars concentration was estimated using the 3,5-dinitrosalicylic acid method [15].

\section{RESULTS AND DISCUSSION}

\subsection{Effect of the [Bmim]Cl on the Growth of Pichia pas- toris GS115}

In order to evaluate the influence of the $[\mathrm{Bmim}] \mathrm{Cl}$ on the ethanol fermentation process of Pichia pastoris GS115, the growth of Pichia pastoris GS115 was first investigated at different $[\mathrm{Bmim}] \mathrm{Cl}$ concentrations in the fermentation medium. Fig. (1) shows the growth curves of Pichia pastoris GS115 at different [Bmim]Cl concentrations form 0.0001 to 5 g. $\mathrm{L}^{-1}$ during the ethanol fermentation process. As indicated in Fig. (1), the [Bmim] Cl had no influence on the growth of
Pichia pastoris GS115 at its concentration less than 0.0001 g. $\mathrm{L}^{-1}$. However, the $[\mathrm{Bmim}] \mathrm{Cl}$ inhibited the growth of Pichia pastoris GS115 at its concentration higher than 0.0001 g. $\mathrm{L}^{-1}$. Moreover, this inhibition became stronger with its concentration increasing. When the $[\mathrm{Bmim}] \mathrm{Cl}$ in the medium reached 5 g. $\mathrm{L}^{-1}$, the yeast had almost no growth and its biomass concentration increased very slowly. Compared to our previous studies $[9,10]$, the influence of $[\mathrm{Bmim}] \mathrm{Cl}$ on the growth of Pichia pastoris GS115 and Saccharomyces cerevisiae had the same characteristic, but Pichia pastoris GS115 was was more sensitive to the $[\mathrm{Bmim}] \mathrm{Cl}$ than Saccharomyces cerevisiae. Under the same [BMIM]Cl concentration, the [BMIM]Cl had more serious inhibition on the growth of Pichia pastoris GS115. The inhibition mechanism of [BMIM]Cl on the growth of Pichia pastoris GS115 might be similar with its inhibition on Saccharomyces cerevisiae, which comes from the interaction between [BMIM]Cl and its cytomembrane.

\subsection{Effect of [Bmim]Cl on the Ethanol Fermentation Process of Pichia pastoris GS115}

Apart from yeast growth, the $[\mathrm{Bmim}] \mathrm{Cl}$ also affects the ethanol formation and fermentable sugars consumption during the ethanol fermentation process of Pichia pastoris GS115. The time courses of ethanol formation and fermentable sugars consumption were measured at different $[\mathrm{Bmim}] \mathrm{Cl}$ concentrations in the fermentation medium and the results are shown in Figs. (2 and 3) respectively. As shown in Figs. (2 and 3), the [Bmim] Cl had no influence on the ethanol formation and fermentable sugars consumption during the ethanol fermentation process of Pichia pastoris GS115 at its concentration is less than 0.0001 g.L ${ }^{-1}$. However, the [Bimim $] \mathrm{Cl}$ negatively affected the ethanol formation and fermentable sugars consumption at its concentration is higher than 0.0001 g. $\mathrm{L}^{-1}$. With the $[\mathrm{Bmim}] \mathrm{Cl}$ concentration 


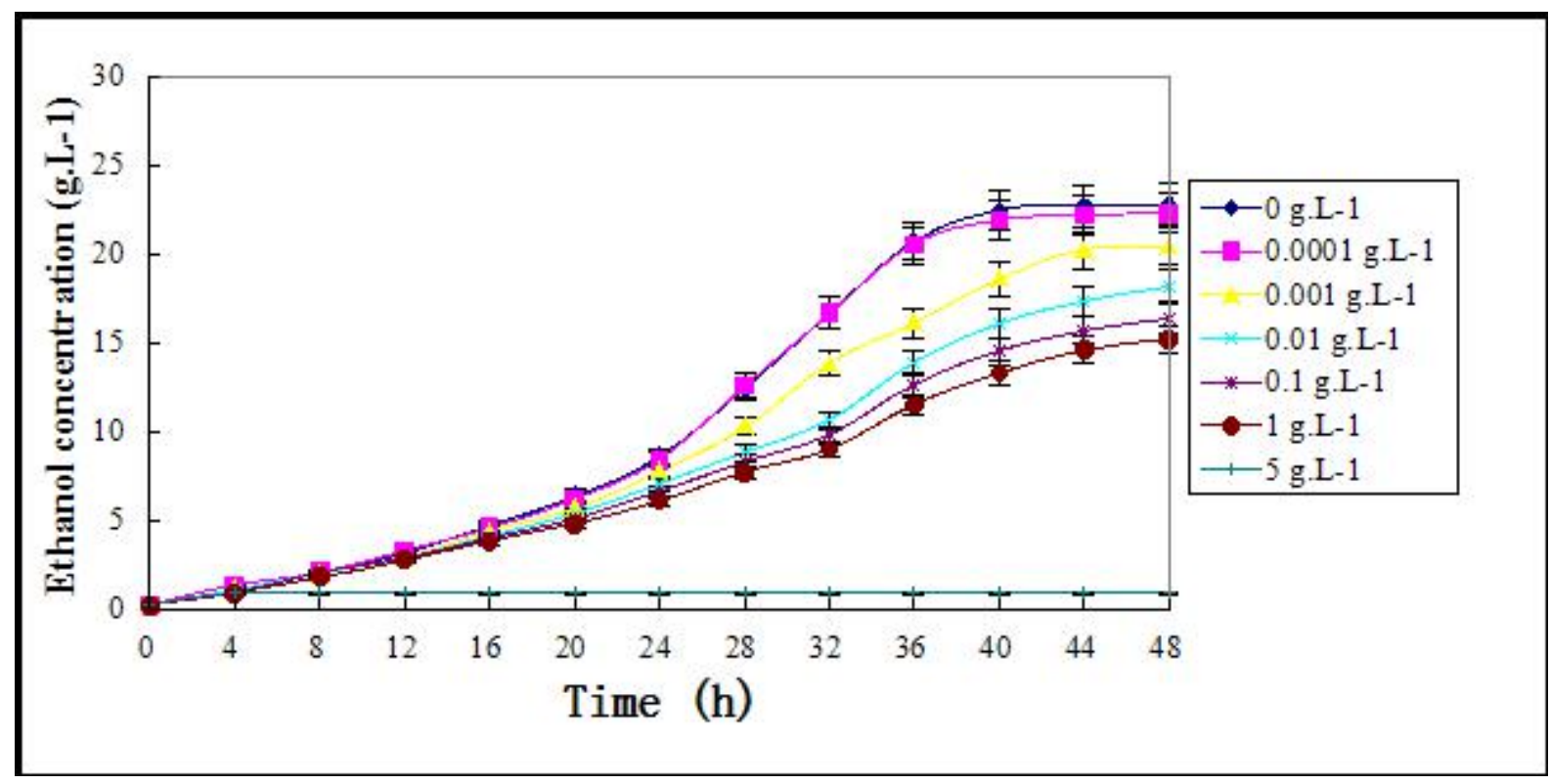

Fig. (2). Time courses of ethanol concentration for ethanol fermentation process under different $[\mathrm{Bmim}] \mathrm{Cl}$ concentrations.

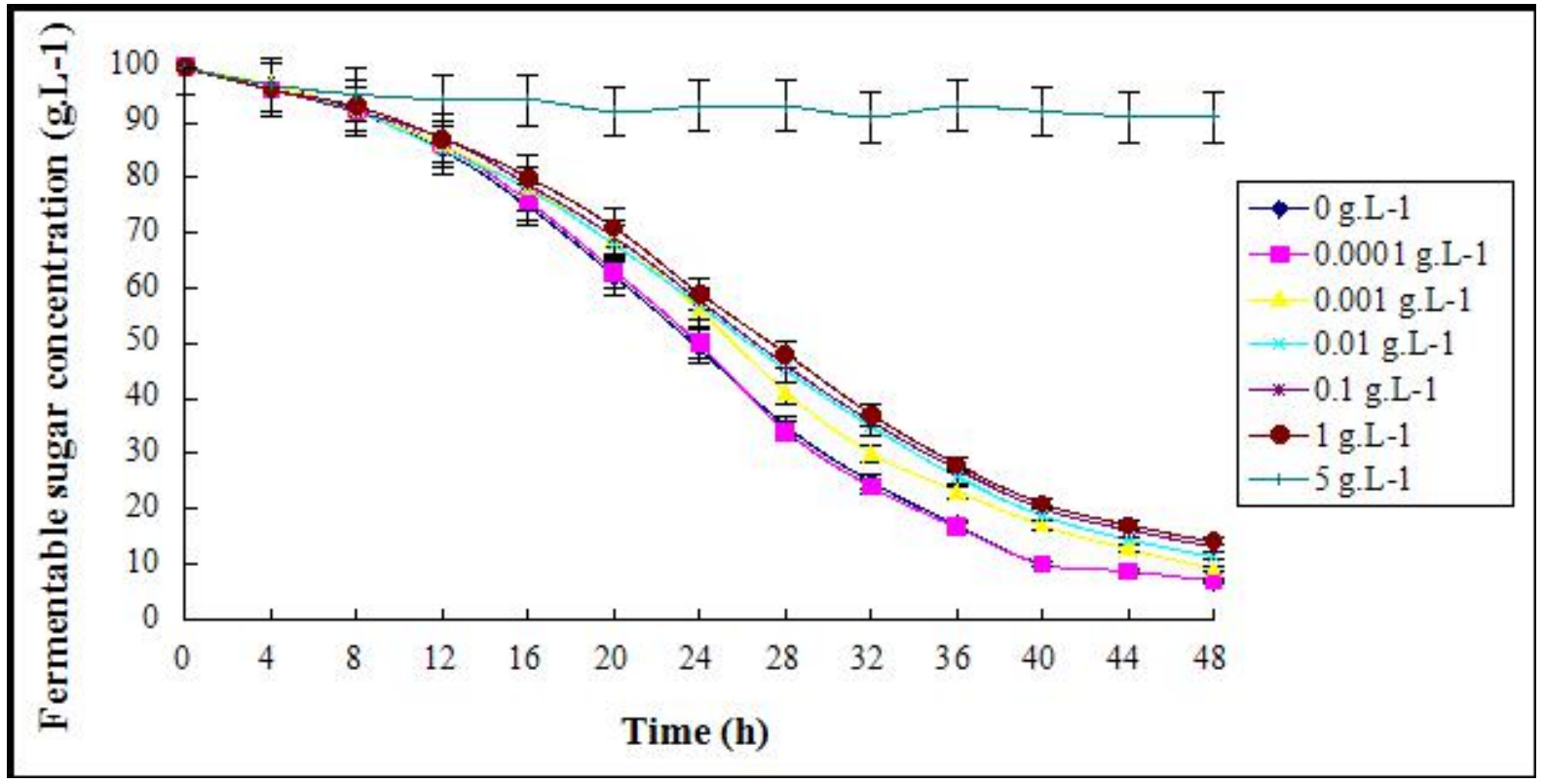

Fig. (3). Time courses of the fermentable sugars concentration for ethanol fermentation process under different $[\mathrm{Bmim}] \mathrm{Cl}$ concentrations.

increasing, the ethanol formation rate and the consumption rate of fermentable sugars both decreased. When the $[\mathrm{Bmim}] \mathrm{Cl}$ in the medium reached $5 \mathrm{~g} . \mathrm{L}^{-1}$, there was almost no ethanol formation and fermentable sugars consumption. Table 1 listed some important parameters during the ethanol fermentation process of Pichia pastoris GS115 at different $[\mathrm{Bmim}] \mathrm{Cl}$ concentrations. As indicated in Table 1, the final biomass and ethanol concentration and the overall ethanol from the fermentable sugars all decreased with the $[\mathrm{Bmim}] \mathrm{Cl}$ concentration increasing, but the final remained fermentable sugars increased. It is obvious that the influence of $[\mathrm{Bmim}] \mathrm{Cl}$ on the growth of Pichia pastoris GS115 was in good agreement with its effect on the ethanol formation and fermentable sugars consumption during the ethanol fermentation process of Pichia pastoris GS115, which implies that the influence of $[\mathrm{Bmim}] \mathrm{Cl}$ on the ethanol formation and fermentable sugars consumption during the ethanol fermentation process of Pichia pastoris GS115 came from its impact on the growth of Pichia pastoris GS115. This is similar with the influence of $[\mathrm{Bmim}] \mathrm{Cl}$ on ethanol fermentation process of Saccharomyces cerevisiae. Compared to the ethanol fermentation of Saccharomyces cerevisiae [9, 10], the $\mathrm{Bmim}] \mathrm{Cl}$ had a more serious effect on the ethanol fermentation process of Pichia pastoris GS115. The ethanol fermentation of Pichia pastoris GS115 had lower final ethanol concentration and overall ethanol yield from the fermentable sugars under the same $[\mathrm{Bmim}] \mathrm{Cl}$ concentration. Comparatively speaking, Saccharomyces cerevisiae was more tolerant to the $[\mathrm{Bmim}] \mathrm{Cl}$ and suitable for ethanol fermentation containing the $[\mathrm{Bmim}] \mathrm{Cl}$ in the medium. 
Table 1. Effect of [Bmim]Cl concentration on the ethanol fermentation process parameters.

\begin{tabular}{|c|c|c|c|c|c|c|c|}
\hline $\mathrm{C}_{\mathrm{i}}\left(\mathrm{g} . \mathrm{L}^{-1}\right)$ & 0 & 0.0001 & 0.001 & 0.01 & 0.1 & 1 & 5 \\
\hline $\mathrm{C}_{\mathrm{b}}\left(\mathrm{g} . \mathrm{L}^{-1}\right)$ & 6.12 & 6.15 & 5.75 & 4.78 & 4.45 & 3.85 & 0.72 \\
\hline $\mathrm{C}_{\mathrm{p}}\left(\mathrm{g} \cdot \mathrm{L}^{-1}\right)$ & 22.9 & 22.4 & 20.5 & 18.3 & 16.5 & 15.3 & 1.1 \\
\hline $\mathrm{C}_{\mathrm{s}}\left(\mathrm{g} . \mathrm{L}^{-1}\right)$ & 6.8 & 7.1 & 9.2 & 11.5 & 13.1 & 14.2 & 91.1 \\
\hline $\mathrm{Y}$ & 0.246 & 0.241 & 0.226 & 0.207 & 0.190 & 0.178 & 0.124 \\
\hline
\end{tabular}

$\mathrm{C}_{\mathrm{i}}$ represents the $[\mathrm{Bmim}] \mathrm{Cl}$ concentration $\left(\mathrm{g} . \mathrm{L}^{-1}\right), \mathrm{C}_{\mathrm{b}}$ represents the final biomass concentration $\left(\mathrm{g} . \mathrm{L}^{-1}\right), \mathrm{C}_{\mathrm{p}}$ represents the final ethanol concentration $\left(\mathrm{g} . \mathrm{L}^{-1}\right), \mathrm{C}_{\mathrm{s}}$ represents the final fermentable sugars concentration $\left(\mathrm{g} . \mathrm{L}^{-1}\right)$, Y represents the ethanol overall yield from the fermentable sugars.

\section{CONCLUSION}

The influence of the $[\mathrm{Bmim}] \mathrm{Cl}$ with different concentrations in the medium on the ethanol fermentation process of Pichia pastoris GS115 was investigated and the main conclusions are as follows:

1) When the $[\mathrm{Bmim}] \mathrm{Cl}$ in the medium was higher than 0.0001 g.L $\mathrm{L}^{-1}$, it inhibited the yeast growth and had a negative effect on ethanol formation. The final biomass and ethanol concentration, and the overall ethanol yield from the fermentable sugars all decreased with the increase of the $[\mathrm{Bmim}] \mathrm{Cl}$ concentration. When the $[\mathrm{Bmim}] \mathrm{Cl}$ in the medium reached $5 \mathrm{~g} . \mathrm{L}^{-1}$, the yeast growth was very slow and nearly no ethanol formed.

2) Compared to the growth and ethanol fermentation of Saccharomyces cerevisiae, the growth of Pichia pastoris GS115 was more sensitive to the $[\mathrm{Bmim}] \mathrm{Cl}$, and its ethanol fermentation had lower final ethanol concentration and overall ethanol yield from the fermentable sugars under the same $[\mathrm{Bmim}] \mathrm{Cl}$ concentration. This work provides useful information on selecting suitable strains for ethanol fermentation containing the $[\mathrm{Bmim}] \mathrm{Cl}$ in the medium.

\section{CONFLICT OF INTEREST}

The authors confirm that this article content has no conflict of interest.

\section{ACKNOWLEDGEMENTS}

This work was supported by the National Natural Science Foundation of China (No. 21176196) and the Collaborative Innovation Center of Catalysis Materials of Hubei Province.

\section{REFERENCES}

[1] Gupta A, Verma J P. Sustainable bio-ethanol production from agroresidues: A review. Renew Sust Energy Rev 2015; 41: 550-67.
[2] Sims R E H, Mabee W, Saddler J N, Taylor M. An overview of second generation biofuel technologies. Bioresour Technol 2010; 101: 1570-80.

[3] Wang Q, Wu Y, Zhu S. Use of ionic liquids for improvement of cellulosic ethanol production. Bioresources 2011; 6: 1-2.

[4] Zhu S, Yu P, Lei M, et al. A mini-review on the lignocellulosic ethanol production by using ionic liquid technology. Energy Educ Sci Tech-A 2012; 30(SI-1): 95-106.

[5] Datta S, Holmes B, Park J I, et al. Ionic liquid tolerant hyperthermophilic cellulases for biomass pretreatment and hydrolysis. Green Chem 2010; 12: 338-45.

[6] Li C, Wan Q, Zhao Z K. Acid in ionic liquid: an efficient system for hydrolysis of lignocellulose. Green Chem 2008; 10: 177-82.

[7] Binder J B, Raines R T. Fermentable sugars by chemical hydrolysis of biomass. Proc Natl Acad Sci 2010; 107: 4516-21.

[8] Zhang Y, Du H, Qian X, Chen E X Y. Ionic liquid-water mixtures: enhanced $\mathrm{Kw}$ for efficient cellulosic biomass conversion. Energy Fuel 2010; 24: 2410-17.

[9] Zhu S, Yu P, Tong Y, et al. Effects of the ionic liquid 1-butyl-3methylimidazolium chloride on the growth and ethanol fermentation of Saccharomyces cerevisiae AY92022. Chem Biochem Eng Q 2012; 26: 105-9.

[10] Zhu S, Yu P, Lei M, et al. Investigation of the toxicity of the ionic liquid 1-butyl-3-methylimidazolium chloride to Saccharomyces cerevisiae AY93161 for lignocellulosic ethanol production. Polish J Chem Technol 2013; 15: 94-8.

[11] Margeot A, Hahn-Hagerdal B, Edlund M, Slade R, Monot F. New improvements for lignocellulosic ethanol. Curr Opin Biotechnol 2009; 20: 372-80.

[12] Meko'o D J L, Xing Y, Shen L L. Production of ethanol from cellobiose by recombinant $\beta$-glucosidase expressing Pichia pastoris: submerged shake flask fermentation. Afr J Biotechnol 2012; 11: 9108-17.

[13] Atala DIP, Costa AC, Filho MR, Mauger F. Kinetics of ethanol fermentation with high biomass concentration considering the effect of temperature. Appl Biochem Biotechnol 2001; 91-93: 353-65.

[14] Zhu S, Wu Y, Yu Z, et al. Simultaneous saccharification and fermentation of microwave/alkali pretreated rice straw to ethanol. Biosys Eng 2005; 92: 229-35.

[15] Miller G L. Use of dinitrosalicylic acid reagent for determination of reducing sugar. Anal Chem 1959; 31: 420-28.

(C) Huang et al.; Licensee Bentham Open.

This is an open access article licensed under the terms of the Creative Commons Attribution Non-Commercial License (http://creativecommons.org/licenses/by-nc/3.0/) which permits unrestricted, non-commercial use, distribution and reproduction in any medium, provided the work is properly cited. 